\title{
Ontologies of Living Beings: Introduction
}

\author{
A. M. Ferner* and Thomas Pradeu ${ }^{\dagger}$
}

Part of a special issue, Ontologies of Living Beings, guest-edited by A. M. Ferner and Thomas Pradeu

Though the history of the interactions between 'biology' and metaphysics is almost as old as Western philosophy itself (Lennox 2001), it seems fair to say that there has been a resurgence of interest in this connection in the last couple of decades (e.g. Hull 1989; Millstein 2009; Clarke 2011; Dupré 2012; Pradeu 2012; Godfrey-Smith 2013; Ferner 2016; Wiggins 2016). Rediscovering this connection brings both opportunities and challenges.

Take, for example, the recent suggestions by certain philosophers of biology, especially John Dupré and co-workers (Dupré 2012), to shift towards a processual view of the living world. The shift, wherein organisms are to be considered processes rather than 'things,' is a dramatic and generative one. However, those readers more firmly positioned within the sphere of analytic metaphysics will know the kinds of objections that processual accounts excite, e.g., from substance-led Aristotelians. Organisms, the Aristotelian says, are substances that undergo processes, but do not exemplify them. (For more general arguments for and against process-based ontologies, see Seibt 2013; Wiggins 2016.)

Albeit prominent, this is just one of many controversies about the metaphysical character of living beings. As originally envisaged, the aim of this special issue was to flesh out this debate alongside others, where the fields of biology, philosophy of biology, and metaphysics overlap. More generally, we had thought to bring together a series of papers examining the various frameworks, or 'ontologies,' within which one can pick out biological individuals (and to examine the relationships between these ontological frameworks). In certain respects, we hope, this special issue displays some of the successes of this project.

It is easy, however, to become overly beholden to ambitions of 'success'-and, as editors, we have found our failures just as, if not more, valuable and interesting.

Our intention for the issue was to bring together contributors from across the philosophical spectrum, to try to nurture dialogue between them on these topics; we asked philosophers of biology, analytic metaphysicians, and historians of science to help us examine the different ways that biological reality can be partitioned. Though strictly speaking they are $s u b$-disciplines, the modes of inquiry and characteristic questions of these areas are sufficiently different for us to label this project 'interdisciplinary' (though others might prefer the term 'multidisciplinary').

Yet interdisciplinarity is difficult. We enter this here not as an excuse (though perhaps we should), but because it's important to emphasize why exactly it is so difficult. We are convinced

*Royal Institute of Philosophy, 14 Gordon Square, London, WC1H 0AR, UK, adamferner@googlemail.com

†ImmunoConcept, UMR5164, CNRS \& University of Bordeaux, 146 Rue Léo Saignat, 33076 Bordeaux, France, thomas.pradeu@u-bordeaux.fr

doi:10.3998/ptb.6959004.0009.004 
that the mode of interdisciplinary research is a promising avenue, but also that success will require the identification of the main obstacles that need to be overcome.

There are, of course, practical obstacles to productive interdisciplinary discussion (Leonelli and Ankeny 2015). It takes many years for an individual to become proficient in the modes and methods, as well as the habitus, of their field. It would take a good many more for that same individual to find their footing in another discipline, and academics working at a high level in more than one discipline are thin on the ground. Moreover, the honing of the skills needed to communicate one's research to non-specialists (or those working outside one's sphere) also represents a considerable time investment. This temporal obstacle is also, inevitably, a financial one, and the luxury to pursue extensive research 'outside' or orthogonal to one's field is one that most employed academics do not have.

At the same time, it's true that there are transferable academic skills, and one might hope that researchers working at a certain level could usefully communicate with others working in related fields. Sometimes, clearly, this hope is fulfilled. Unfortunately, optimism has its shortcomings. We are surely not alone in noticing the confusions that arise - at 'interdisciplinary' conferences, debates, and so forth-from terminological overlaps. When philosophers of biology talk about identity, ontology, self, substance and process, they can mean something entirely different than what an analytic metaphysician might, when she uses those selfsame terms.

'Identity' is perhaps the most commonly confused. For analytic metaphysicians, 'identity' is a very particular metaphysical-cum-logical relation (e.g. Perry 2002; Macdonald 2005; Lowe 2009). For philosophers of biology (and biologists) it can be used to mean a variety of things. In some contexts of biology and philosophy of biology, 'identity' is taken to mean the peculiar properties of a given thing. Some biologists talk about the genome or the histocompatibility system (the 'Human Leukocyte Antigens,' or 'HLA' in humans) as the 'identity card' of the organism, because it makes of each living being a unique being (e.g. Dausset 1981). As such, however, these discussions about the genome and the HLA system are not concerned with the specific metaphysical relation that holds e.g., for a living being between an earlier and a later time.

This terminological confusion could perhaps be easily resolved, but there are others-around words like 'substance,' for instance - that require a considerable amount of conceptual and historical unpacking, even after they've been identified. Several philosophers of biology (e.g., Hull 1992) have proposed rejecting the substance-based view of individuality on the pretext that living things do not retain their material substance unchanged throughout their existence (because they can undergo maturation, metamorphosis, etc.). But metaphysicians need not think that substance must remain materially unchanged (and indeed few of them do). The risk, then, is that philosophers of biology and metaphysicians are simply not talking about the same things.

On the other side of the divide, most metaphysicians rely heavily on thought experiments, even when examining issues directly related to the living world, e.g., brain transplantation (e.g. Parfit 1984; Olson 1997, 2007). Further, when most metaphysicians talk about 'organisms,' they tend to mean a mammal or a familiar vertebrate, even though philosophers of biology have pointed out for decades that the ambit of the term is far greater, and that taking into account the actual diversity of the living world could have massive consequences for metaphysical debates (e.g. Hull 1978). Discussions over 'animalism' (the view that each of us is an organism of the species Homo sapiens and that we persist as animals; see Blatti and Snowdon 2016) illustrate this tension between 'vertebrate-centrism' and wider approaches to what organisms are (Dupré 2014).

The result is failure of communication. People talk past each other-indeed, they think past each other-and often fail to realise it. 
Interdisciplinary communication is epistemically perilous. Not only is there a risk of being misunderstood, there is also the greater risk of not being aware of being misunderstood-and thus being unable to correct consequent mistakes. Interdisciplinary work (produced by an individual author) inhabits an epistemic no-man's land, where the ability of intellectual communities to critically assess the piece is impaired by its correlative knowledge requirements. These epistemic perils are rarely tackled head-on, to the detriment of interdisciplinary discussion. This, predictably, is a result of the current political milieu in higher education; in an academic world dominated by notions of 'impact,' there are few resources to spare on improving, e.g., the structure of conferences, such that they might be more amenable to cross-disciplinary chatter.

Downstream of the practical obstacles are certain conceptual and methodological obstacles to interdisciplinary discussion. Looking through the essays collected in this issue, it is clear that there are different methodologies at play: the 'philosophers of biology' tend to focus on specific, detailed biological inquiry, and to engage directly with the science; the 'metaphysicians,' by contrast, tend towards varieties of conceptual analysis, and biological data is used primarily in examples either to corroborate or to challenge specific metaphysical assumptions. These are broad brush-stroke characterisations, but they point towards a potential conceptual block. The picture of reality described by science is the product of certain modes of conceptualisation (for example, crudely put, microscopes pick out different entities than the ones we pick out in our everyday lives); the kind of conceptual analysis practiced by many analytic metaphysicians is deeply tied to our (everyday) ways of thinking. There is a possibility, then, that the pictures might not match up - and the biological individuals picked out in one sphere might be invisible in the other.

None of this is to say that collaboration between disciplines (or sub-disciplines) is not desirable or not often productive. Again, however, it is worthwhile focussing on how it might be productive (and thus why it might be desirable). Interaction between different spheres might be generative without being communicative; for example, a metaphysician might hear a biologist describe some cellular process and find it a powerful metaphor for some philosophical concept. This is a kind of lower-order benefit (as new perspectives often emerge from random encounters). Higher-order benefits, by contrast, involve actual communication and uptake and include the investigation of problems in one field using conceptual tools from another. It is the latter benefits which, presumably, the readers of this journal are aiming for-and it's worthwhile to make this explicit.

So: interdisciplinary projects, while important, are difficult. Recognising this, we might begin to combat the issues that assail them. How? We could, for instance, begin challenging the notion of the 'polymath' who can move fluidly between diverse fields; such people may exist, but they are considerably scarcer than the current interdisciplinarity trend allows. Further, we could critically examine the notion of 'interdisciplinarity,' and the motivations for pursuing it.

More importantly, perhaps, we should create and nurture new structures to host interdisciplinary discussion. These structures will appear in conference spaces, in classrooms, in books, and in journals. Philosophy, Theory, and Practice in Biology is one such journal. In addition to the virtues of being peer-reviewed, online, and fully open-access, its 'position papers' and 'comments' capacity mean that it can accommodate extensive, genuine debate. Furthermore, for this special issue, the editorial board have allowed us to give each contribution an individual editorial introduction (rather than examining them all in a generic overview). In these introductions, we have tried to place the contributions in helpful contrapositions, to draw out complementary elements, and to trace a distinct narrative throughout the collection. We hope that the result overcomes some if not all of the obstacles to interdisciplinarity outlined above. 


\section{Acknowledgments}

T. P. has received funding from the European Research Council (ERC) under the European Union's Horizon 2020 research and innovation programme-grant agreement n ${ }^{\circ} 637647$ - IDEM.

\section{Literature cited}

Blatti, S., and P. F. Snowdon, editors. 2016. Animalism: New Essays on Persons, Animals, and Identity. Oxford: Oxford University Press.

Clarke, E. 2011. “The Problem of Biological Individuality.” Biol Theory 5: 312-325.

Dausset, J. 1981. “The Major Histocompatibility Complex in Man.” Science 213: 1469-1474.

Dupré, J. 2012. Processes of Life: Essays in the Philosophy of Biology. Oxford: Oxford University Press.

Dupré, J. 2014. “Animalism and the Persistence of Human Organisms." South J Philos 52: 6-23. doi:10.1111/sjp.12065.

Ferner, A. M. 2016. Organisms and Personal Identity: Biological Individuation and the Work of David Wiggins. Routledge.

Godfrey-Smith, P. 2013. Darwinian Individuals. In From Groups to Individuals: Evolution and Emerging Individuality, edited by F. Bouchard and P. Huneman, 17-36. Cambridge, MA: MIT Press.

Hull, D. 1992. "Individual." In Keywords in Evolutionary Biology, edited by E. F. Keller and E. A. Lloyd, 181-187. Cambridge, MA: Harvard University Press.

Hull, D. L. 1989. The metaphysics of evolution. Albany: State University of New York Press.

Hull, D. L. 1978. A Matter of Individuality. Philos Sci 45: 335-360.

Lennox, J. G. 2001. Aristotle's Philosophy of Biology: Studies in the Origins of Life Science. Cambridge: Cambridge University Press.

Leonelli, S., and R. A. Ankeny. 2015. "Repertoires: How to Transform a Project into a Research Community." BioScience 65: 701-708. doi:10.1093/biosci/biv061.

Lowe, E. J. 2009. More Kinds of Being: A Further Study of Individuation, Identity, and the Logic of Sortal Terms, 2nd ed. Wiley-Blackwell.

Macdonald, C. 2005. Varieties of Things: Foundations of Contemporary Metaphysics. Oxford: Blackwell Pub.

Millstein, R. L. 2009. "Populations as Individuals." Biol Theory 4: 267-273. doi:10.1162/biot.2009.4.3.267.

Olson, E. T. 1997. The Human Animal: Personal Identity Without Psychology. Oxford: Oxford University Press.

Olson, E. T. 2007. What Are We?: A Study in Personal Ontology. Oxford: Oxford University Press.

Perry, J. 2002. Identity, Personal Identity, and the Self. Indianapolis: Hackett Pub.

Pradeu, T. 2012. The Limits of the Self: Immunology and Biological Identity. Oxford: Oxford University Press.

Seibt, J. 2013. "Process Philosophy." In The Stanford Encyclopedia of Philosophy, Fall 2013 edition. Edited by E. N. Zalta. https://plato.stanford.edu/archives/fall2013/entries/process-philosophy/.

Wiggins, D. 2016. “Activity, Process, Continuant, Substance, Organism.” Philosophy 91: 269-280. 
(C) 2018 Author(s).

This is an open-access article distributed under the terms of the Creative Commons AttributionNonCommercial-NoDerivatives 4.0 International license, which permits anyone to download, copy, distribute, or display the full text without asking for permission, provided that the creator(s) are given full credit, no derivative works are created, and the work is not used for commercial purposes.

ISSN 2475-3025 